\title{
Research on Tourism Development and Enlightenment of Taiwan Flying Cow Ranch
}

\author{
Mingzhu Liang, Zhengying Guo \\ Department of Tourism Management, School of Management, Jinan University, Guangzhou, China \\ Email:emmagzy@126.com
}

How to cite this paper: Liang, M.Z. and Guo, Z.Y. (2019) Research on Tourism Development and Enlightenment of Taiwan Flying Cow Ranch. Journal of Service Science and Management, 12, 132-151. https://doi.org/10.4236/jssm.2019.122010

Received: January 2, 2019

Accepted: February 9, 2019

Published: February 12, 2019

Copyright $\odot 2019$ by author(s) and Scientific Research Publishing Inc. This work is licensed under the Creative Commons Attribution International License (CC BY 4.0).

http://creativecommons.org/licenses/by/4.0/

(c) (i) Open Access

\begin{abstract}
As the emphasis on leisure agriculture is increasing in the tourism market, Flying Cow Ranch has become a typical example of many experiential agriculture farms with its unique resources, environmental advantages and educational significance. Firstly, this paper expounds and analyzes the development status and management model of Flying Cow Ranch, and uses the method of ASEB to analyses the visitor experience. Then this paper reviews the dynamic mechanism and operation mechanism of the ranch's development comprehensively. Finally, this paper summarizes seven successful business elements and future development trends of Flying Cow Ranch.
\end{abstract}

\section{Keywords}

Flying Cow Ranch, Leisure Agriculture, Tourism Development, Tourists

Experience, Environmental Education, Dynamic and Operation

Mechanism, Enlightenment

\section{Introduction}

With the accelerating industrialization and urbanization process, the tension brought by the city to the residents is increasing, and the environmental quality of the city is declining. This makes urban residents eager to return to nature and find the essence of life, which pushing the development of leisure agriculture tourism. On the other hand, the increasing number of people is willing to travel on weekends and short holidays, therefore, the rural areas that around the city have become the first choice of short-distance travel for people, especially for parent-child travel. In addition, the government of the city has focused on agriculture, rural development, as well as the tourism, and has brought together the two high-profile things. Therefore, agriculture and tourism promote each other to achieve a win-win situation. 
Leisure agriculture in China has developed rapidly in recent years. More and more leisure farms have been established. The combination of culture, health care and leisure agriculture tourism has promoted the rise of many leisure agricultural resorts and leisure agricultural towns, providing a richer form for the development of leisure agriculture, and also emerging a number of quality projects, such as Beijing International Flower Port, COFCO Smart Farm, Jingdong Chestnut Grand View Garden, Siping Ancient Village, etc. However, there are still many problems, such as the monotonous and similar projects, the low participation of tourists, and the poor environment. Meanwhile, leisure agriculture in Taiwan started earlier and developed more maturely. It has achieved a considerable scale and produced the good social, economic and ecological benefits. Therefore, the successful experience of Flying Cow Ranch has a very important role and enlightenment for the development and transformation of leisure agriculture in China.

\section{Literature Review}

\subsection{Leisure Agriculture and Leisure Farms}

Cheng [1] proposes that leisure agriculture is a kind of agricultural business activity, which refers to the use of pastoral landscape, natural ecology and environmental resources, combined with agriculture, forestry, animal husbandry and fishery production, agricultural management activities, rural culture and farmer life to provide leisure services for the public, thereby enhancing their agricultural and rural experience. Zhang et al. [2] believes that leisure agriculture is a new type of agriculture that integrates production, sales, sightseeing, leisure, entertainment experience, popular science education and ecological protection based on production, life and ecological resources related to agriculture, rural areas and farmers. Tourism and agriculture intersect in this type of industry. In general, there are two types of emphasis on the definition of leisure agriculture: one category considers that leisure agriculture is a form of agricultural management [3]. Another category considers leisure agriculture to be a leisure tourism activity [4]. This article believes that leisure agriculture is an agricultural tourism activity taking the production of agriculture, forestry, animal husbandry and fishery production, rural scenes, and farmer's labor life as main attractions, and it integrates agricultural production and processing, technology application, art processing and tourist participation experience activities.

Domestic and foreign scholars' researches on leisure agriculture mainly focus on features, types, development status, constraints, reference to development experience, tourism development and planning and design of specific cases. Guo [5] points out that leisure agriculture has dual attributes of agriculture and tourism, with six characteristics of production, viewing, entertainment, participation, culture and market; Zhang [6] believes that leisure agriculture has distinctive characteristics of blending with nature and cultural synthesis. Therefore, the most important feature of leisure agriculture is the duality of industry and the 
comprehensiveness of culture. Liu [7] proposes that leisure agriculture has the characteristics of agricultural production, marketing, rural life, rural landscape, rural culture, rural ecology, experience education and leisure recreation.

The development of leisure agriculture is mainly distributed in the suburbs of large cities or in typical agricultural areas [4] [8]. Different regions will have different modes of leisure agriculture due to economic, social, environmental and natural conditions. From the perspective of product types, there are mainly seven modes of leisure agriculture, such as farmhouse stay, village tourism, leisure vacation, popular science education, agricultural participation, rural agriculture, folk customs, etc. [9] [10]. From the perspective of business modes, there are agricultural, industrial, service, and experience economic models [11]. In terms of the business type of leisure agriculture, Yuan [8] believes that there are five categories of leisure agriculture, such as agricultural parks, sightseeing and leisure farms, education and technology farms, forest parks and folk sightseeing villages; Liu et al. [12] propose the organization model of leisure agriculture operation such as farmhouse stay, leisure farms, leisure agricultural parks and folk villages; Guo [5] divides leisure agriculture into urban suburbs, surrounding areas, featured villages, bases driven and resources driven according to the location, and divided the farms into sightseeing farms, leisure farms, science and technology farms, ecological farms, leisure fishing parks, citizen farms and agricultural parks according to the function.

It can be seen that leisure farm is an important carrier of leisure agriculture, while ranches are farms that based on grassland ecological resources and regarding animal husbandry as core industry. It is an industrialized operation subject under the subdivision of leisure farms. At present, there are 20 leisure and sightseeing pastures as boutique agricultural and rural tourism attractions promoted by the Ministry of Agriculture in China, the development of leisure pastures is in its infancy.

\subsection{Experience of Leisure Agriculture in Taiwan}

Leisure agriculture in Taiwan started in the early 1960s and was the first region in China to develop recreational agriculture. Its development has experienced a historical process from small to large, from weak to strong, from non-standard to normative [13]. In the study of leisure agriculture in Taiwan, some scholars believe that the authorities' attention and policy support, prominent themes and cultural construction, rational planning and layout, characteristic products and innovative management are the most creative aspects of the successful experience of leisure agriculture in Taiwan [14] [15] [16] [17]. Zhou et al. [18] also point out that the characteristics, ecologicalization, legalization, health and digitization of leisure agriculture in Taiwan are valuable to learn. From the perspective of experience economy, Geng [19] believes that diversely and highly engaged leisure agricultural experience activities are the core experience of agricultural transformation in Taiwan. 
Compared with Taiwan, the development of leisure agriculture in mainland of China is at the initial stage of development basically. Although a certain number of agricultural leisure project parks have been built, it pays more attention on quantity rather than quality and lacks sustainability. In that case, there is still a lot to learn.

\section{Case Overview}

\subsection{Ranch Overview}

Flying Cow Ranch is a leisure ranch which is famous for its beautiful scenery in Taiwan. Located in Tongxiao Town of Miaoli County, it was formerly known as the Central Youth Cottage Rural Village established in 1975. It was transformed into a leisure farm in 1995 and officially opened as Flying Cow Ranch. The pasture stretches over a low-altitude gentle slope about $180 \mathrm{~m}-270 \mathrm{~m}$. There is a wide variety of butterflies and groups of cows and goats where is far from the city. The environment is quiet and like a paradise.

Moreover, the ranch was the filming spot of the TV series "One Cut Plum" and "Lavender". It has become famous in the international market through these idol dramas, attracting a large number of domestic and foreign tourists to visit. Besides, the beautiful natural environment here has gradually become the popular wedding photography location for the newlyweds.

\subsection{Development Status}

\subsubsection{Ranch Resources}

1) Rich and diverse natural resources

In addition to the grassland for landscape and recreation, a large jungle area is preserved in Flying Cow Ranch; trees are planted around the landscape area and the scenic trail to maintain a complete ecosystem of biodiversity. The ranch has also particularly planned the theme parks such as butterfly ecology, water ecology (waterfowl, aquatic plant pool, waterwheel, etc.) and animal ecological zones (cow, sheep, rabbit, horse, etc.), emphasizing the interactive experience between human and nature. In the eco-region, cattle and flocks walk on the grasslands to interact with tourists; Organic farms are planted with vanilla crops and organic vegetables, using cow and sheep manure as natural fertilizers, allowing visitors to taste the freshest and safest ingredients; Water ecological zone is a small sewage treatment site, which fully utilizes the characteristics of aquatic plants to carry out the purification of the water cycle, and allows aquatic insects and animals to have habitats. The scenery of Flying Cow Ranch is shown in Figure 1.

2) Unique landscape resources

Flying Cow Ranch has attractive landscape resources besides its ecological resources. The landscape is designed by a famous Japanese landscape architect. It combines the concepts of nature and aesthetics to create an open, laidback, green and stress-free space. In addition, the natural mountain barriers and the beautiful forests make the entire pasture full of tranquility. Most of the buildings 


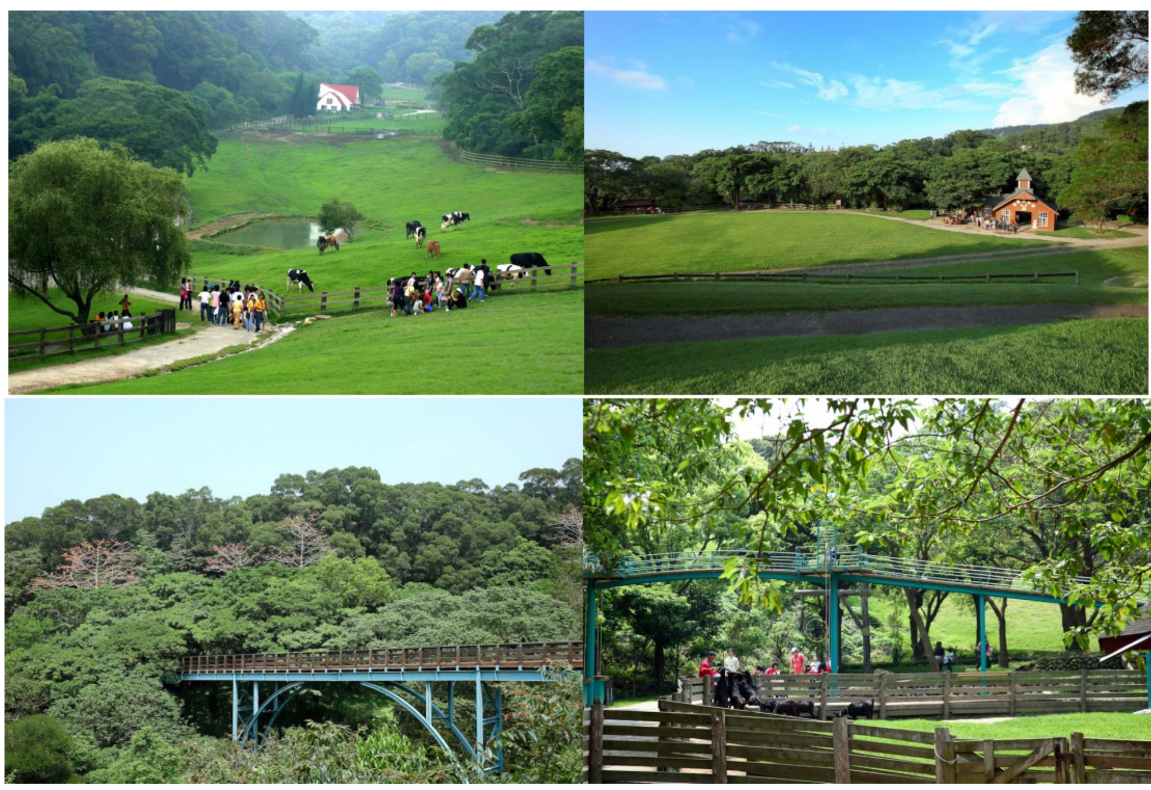

Figure 1. Scenery of flying cow ranch.

in the pasture are wooden in the shape of European spires. In terms of styling and color, it is fully integrated with nature, therefore, it has an aesthetic effect. The ingenious combination of natural and artificial landscapes forms a unique landscape resource for the pasture.

3) Attractive humanities resources

Visitors can not only enjoy natural landscape and agricultural landscape in the ranch, but also can experience the rural life here. The multi-purpose pasture life experience activities and educational explanation activities make it have the most precious humanistic features.

\subsubsection{Functional Division}

As posted in Figure 2, the main body of the ranch is divided into three major areas, namely, the ranch ecological area mainly focusing on the natural ecology and outdoor activities, the DIY.BBQ.Camping area mainly based on leisure and entertainment, and the center service area focusing on rest and various experience education activities.

As can be seen from the figure upon, the three major regions of Flying Cow Ranch are relatively independent, but they are communicative and interconnected. This shows that Flying Cow Ranch focuses on resource optimization and resource integration innovation based on the experience perception of visitors.

1) DIY·BBQ.Camping Area

This area is a concentrated area for leisure activities, which is convenient for unified management. First of all, DIY classrooms are brought together here, so that visitors can choose and make appointments after comparing several DIY activities, or arrange time to concentrate on DIY activities. Secondly, it provides three sites as camping center, which reduces the phenomenon of camping everywhere, guarantees the safety of tourists and helps protect the environment. 


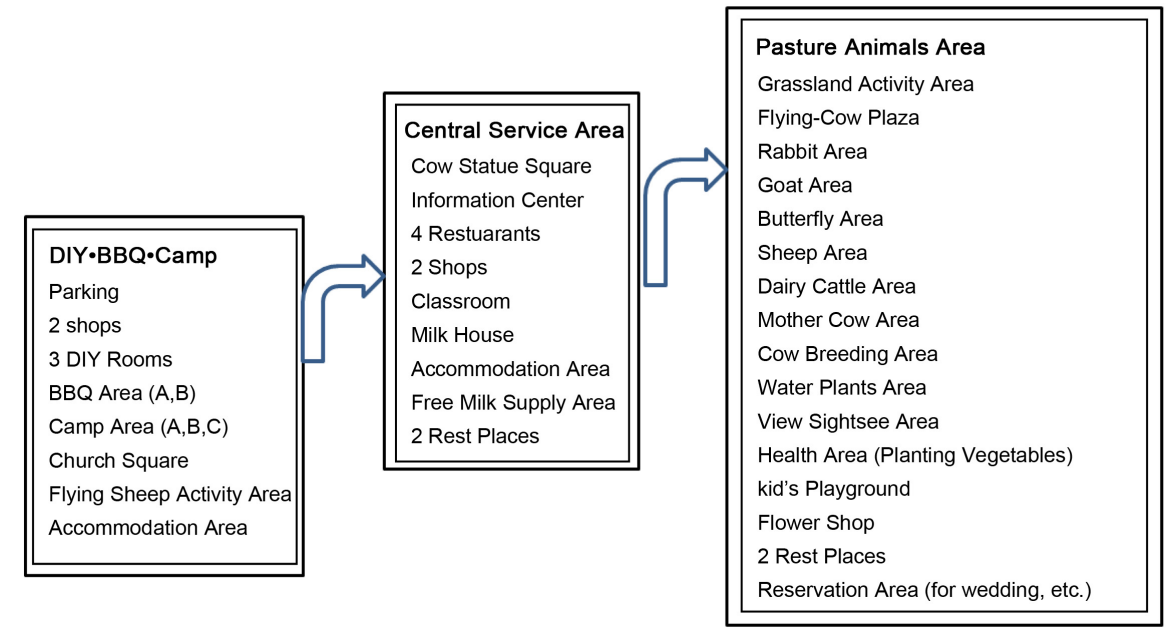

Figure 2. Functional division of flying cow ranch.

In addition, the area is in the downwind direction of the whole scenic spot, arranging $\mathrm{BBQ}$ in this area is conducive to rapid dissipation of the barbecue smoke and prevent pollution of the scenic spot air. Figure 3 presents the photos of children in DIY room.

2) Ranch Ecological Area

This area is the largest of the three functional areas, including grassland activity areas, recreational trails, a variety of animal areas, organic farms and other varied ecological landscape. It was originally a prairie where cattle and sheep were raised, then it has become a perfect place to get close to nature and relax with accessibility, enjoyability and experiential after resource integration. In the scenic map, the ranch also provides three different recommended routes for parent-child experience interaction, ecological life and healthy hiking according to the tourists' needs in this area. Pictures of this area are shown in Figure 4.

3) Center Service Area

This area provides visitors with a variety of services, including catering, accommodation, travel souvenirs, and experience classes. Located in the middle of the scenic spot, it achieves perfect connection with the other two regions. Although it does not occupy a large space, it can be used as a starting point, an ended point and a half-way rest point for tourists. It provides different services for tourists who are in different conditions, including information consultation, receiving free milk, dining, accommodation, leisure, souvenir sales and experience education classes. Photos of this part are presented in Figure 5.

\subsubsection{Service Facilities}

The ranch has a total area of 120 hectares and the existing service facilities cover an area of 50 hectares. There are about 60 staffs, most of whom are residents near the ranch. They can provide educational explanation activities, camping, food and beverage, meetings and other services. The perfect service facilities provide the hardware support for tourists to play in the pasture, and it is also an 


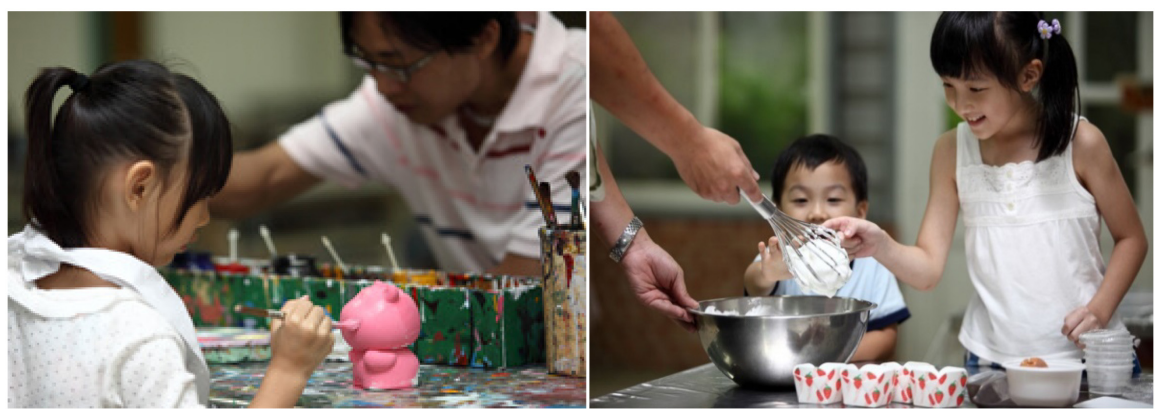

Figure 3. DIY·BBQ·Camping area.

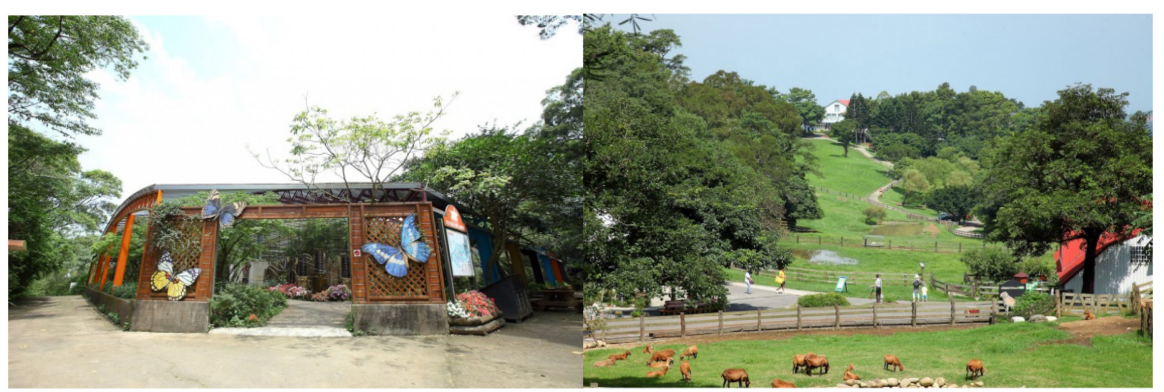

Figure 4. Ranch ecological area.

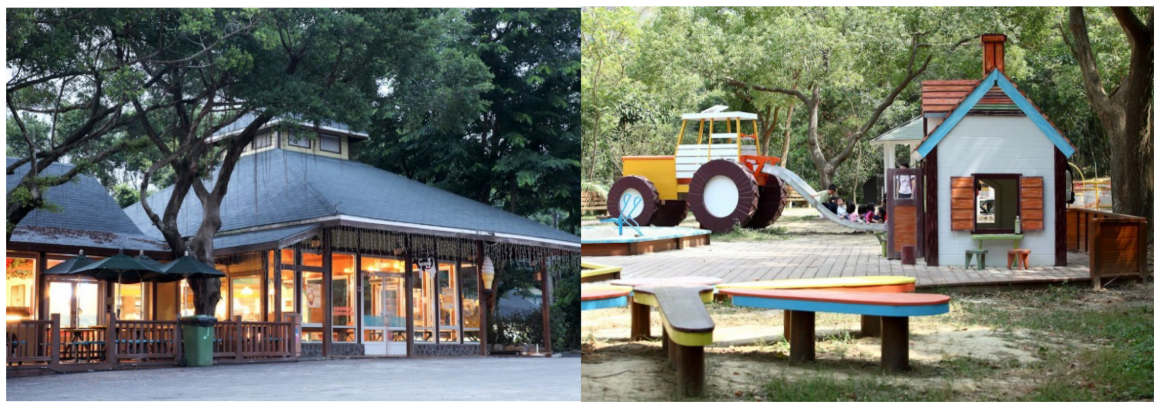

Figure 5. Center service area. Note: All pictures above are from the official website of flying cow ranch.

important element that affects the satisfaction of the visitors experience [20]. Table 1 shows the number of facilities in detail.

\subsubsection{Experience Activities}

The core of leisure agriculture is experience activity. Even if a leisure farm has beautiful ecology landscape, diverse products, and rich rural culture, if there is no experience activities, tourists can't participate and get intellectual and emotional gains. The successful operation of the leisure ranch depends on the series of experience products, such as educational experience, entertainment experience, aesthetic experience and accommodation experience [21]. The experience-based tourism products of Flying Cow Ranch are the highlights of its development and are also important items for its successful operation.

The needs of visitors to the Flying Cow Ranch are summarized below:

1) Desire to escape from the hustle and bustle, have a leisure vacation and 
Table 1. Major service facilities and carrying capacity.

\begin{tabular}{|c|c|c|}
\hline Meeting Room & $\begin{array}{l}\text { Accommodation (A total of } 60 \\
\text { rooms for more than } 200 \\
\text { people) }\end{array}$ & Restaurants \\
\hline \multirow[t]{5}{*}{$\begin{array}{l}1 \text { meeting room for } 120 \\
\text { people }\end{array}$} & $\begin{array}{c}\text { Camping Area } \\
\text { (6 people per cent) }\end{array}$ & $\begin{array}{l}\text { Chinese Food Restaurant } \\
\text { (Flying Cow Restaurant) }\end{array}$ \\
\hline & $\begin{array}{c}\text { Suites } \\
\text { (3 suites for } 5 \text { people;11 suites } \\
\text { for } 4 \text { people; } 1 \text { suite for } 2 \text { people) }\end{array}$ & Cow's Hot Pot \\
\hline & $\begin{array}{l}\text { Hotel } \\
\text { (5 rooms for } 3 \text { people;35 } \\
\text { rooms for } 4 \text { people; } 5 \\
\text { rooms for } 2 \text { people) }\end{array}$ & $\begin{array}{l}\text { Italian Food Restaurant } \\
\text { (Red Barn Restaurant) }\end{array}$ \\
\hline & & Fast Food Restaurant \\
\hline & & BBQ \\
\hline
\end{tabular}

Note: The data comes from the official website of flying cow ranch.

Relaxation.

2) Desire to take part in leisure activities with family and friends.

3) Long for children to get close to nature and get an education, grow up with their children through parent-child interaction activities.

Based on this, Flying Cow Ranch develops a variety of experiential tourism products to meet the different needs of tourists, as posted in Figure 6 .

1) Educational Experience

One of the characteristics of Taiwan's leisure agriculture is the combination of leisure and education, and the mixing of entertaining and learning. The project design is full of creativity, providing a rich agricultural intellectual journey to attract visitors to experience.

a) Group teaching and explanation: In terms of static education, the farm has a manual for explaining the dairy cow ecological education, a manual for plant ecological explanations, etc. In terms of dynamic education, the outdoor-class experience activities are carried out, and the commentator will explain the cow ecology to children. Children will experience the mystery of ecology, understand the cultivation process and growth status of crops, learn the types and habits of animals and plants, get the working conditions of farmers and the operation process of farming, and acquire scientific knowledge.

b) Being cowboys, milking; catching ducks and feeding ducks: Visitors can learn farming and production status of livestock by personally experiencing farming activities. In this situation, children may feel the joy of labor, and adults can be relaxed.

2) Entertainment Experience

a) $\mathrm{BBQ} \&$ Camping: $\mathrm{BBQ}$ and camping make visitors get the joy of self-sufficiency and experience different kinds of life which can be an unforgettable memory. Through these activities children are no longer the flowers of the greenhouse. 


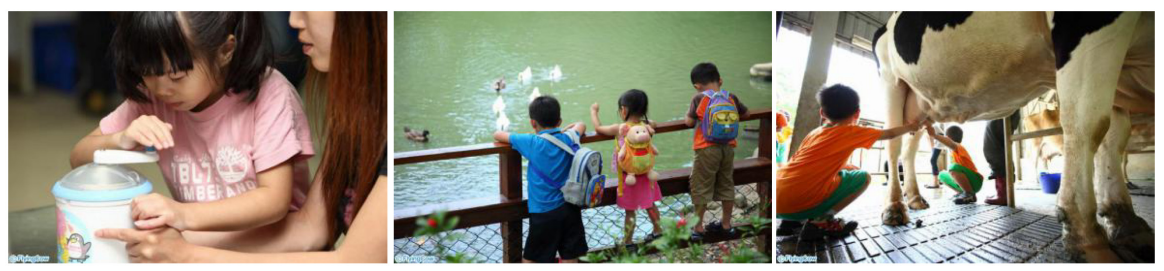

Figure 6. A variety of experience activities.

b) DIY: By making ice cream, milk biscuits, pudding and other dairy food by themselves, visitors can understand the manufacturing methods and process of the food, and enhance their hands-on ability. Visitors can not only get healthy dairy products as souvenirs, but also obtain opportunities for interaction between parents and children or friends.

3) Aesthetic Experience

The best leisure time is to stay away from the hustle and bustle city, enjoy the blue sky and white clouds, appreciate the beautiful forest and grassland, get the opportunity to relax, experience the quiet and leisure life of the country, and improve relationship with the families. Flying Cow Ranch uses these elements to provide a simple and rustic landscape that attracts a wide range of tourists.

In general, during the development of experiential tourism products, Flying Cow Ranch follows three essential elements of experience: personality, emotionality, and participation.

a) The ranch provides personalized DIY activities and focuses on the production of milk products. It not only emphasizes the participation of tourists, but also distinguishes itself from the homogenous experience activities of other leisure farms.

b) The emotional elements are expressed in various activities. Flying Cow Ranch's slogan-“Everyone should have their own ranch."-arouses tourists' dream of possessing their own "Utopia" and pushes them to escape from the reality. In addition, the tourism products of the ranch are very warm and sweet, full of childlike interest, awakening tourists' childhood memories and attracting the attention of children.

\subsubsection{Featured Products}

In addition to experiential tourism product, creative agricultural product is an important element of a leisure farm that distinguishes it from other similar farms [22]. The biggest feature of Flying Cow Ranch is the cows, so its special products are all related to milk or cows. By converting milk into characteristic experience activities or deriving creative products through production, life, and ecological interfaces, visitors can create individual creative cheese products, participate in making clay cows sculptures or creative paintings with the theme of flying cows.

The ranch also produces dairy products of its own brand for sale, which can be bought at supermarkets. The business philosophy of using self-produced dairy products as a gift is both a creative idea for milk culture and encourages 
visitors to enjoy creative ideas. In addition to dairy-related products, visitors to the Flying Cow Ranch can also participate in the cultivation, watering, weeding and other activities of organic vegetables, at the same time, the ranch also sell these organic vegetables as green food.

\subsection{Business Management}

\subsubsection{Business Philosophy}

Flying Cow Ranch holds the concept of "respecting nature" to plan and operate.

1) Brand Image

The brand image of the scenic spot is to win the loyalty of tourists and create a competitive advantage. It is the self-recognition generated from the comprehensive operation and management of the scenic spot, and thus the image recognized by the tourists supports the continuity of the tourist attractions [23]. Green, white and blue are the main colors of Flying Cow Ranch's brand image. Green represents the sustainable ecology of nature, white represents healthy dairy production, and blue represents a joyful holiday.

As shown in Table 2, this paper analyzes the establishment process of the ranch's brand image in a table manner:

Truthly, goodness and beauty are interpretation of the true meaning of life, and also the core value concept of the ranch's brand image; Production, ecology, and life reflect the pasture's business philosophy of "three-in-one", Integrating their products with natural environment into life; health, nature and joy are the brand values that the ranch brings to visitors, enabling visitors to benefit from the operation of the ranch.

What's more, Flying Cow Ranch has shaped the image of a cow with wings. There are sculptures of flying cows everywhere in the pasture. The catering service, processed products and souvenirs are all based on the theme of "Flying Cow". Through high-frequency image display and providing high-quality products and services, the brand is deeply rooted in the hearts of the people.

2) Service Strategy

Flying Cow Ranch makes their service strategies according to different needs of visitors at their different life stages.

a) Childhood

Children need broad nature environment and space to play freely. The ranch provides a wide range of green spaces for children to play in order to meet their needs.

b) Adolescence

Table 2. Analysis of flying cow ranch brand image.

\begin{tabular}{cccc}
\hline Interpretation of life & Truth & Goodness & Beauty \\
\hline $\begin{array}{c}\text { Achieve the value of } \\
\text { resources }\end{array}$ & Production & Ecology & Life \\
Visitors benefits & Health & Nature & Joy \\
\hline
\end{tabular}


Young people need a recreational environment where they can carry out group activities, experience nature and relax. The ranch offers activities teenagers like, such as camping, barbecue and so on.

c) Wedding period

Newlyweds need beautiful scenery to take wedding photos. The ranch is the shooting place of many film and television dramas. It has a variety of natural resources, which can present different landscapes in different seasons, and provides a comfortable environment for newlyweds to spend their honeymoon here.

d) Parent-child period

During this period, busy couples want to make up for their less accompanying to children on weekdays, and hope to bring a healthy and educational activity to children on weekends or holidays, while enhancing the intimacy with children. The ranch provides rich experience activities and eco-tourism activities for parent-child tourism.

e) Elderly period

What is most needed in old age is healthy travel, meanwhile, the elderly usually have a nostalgic mood. At the ranch, there is a healthy natural environment and organic food, also there is a rural life that the elderly yearn for.

3) Service Target

Flying Cow Ranch aims to provide visitors a full range of leisure experiences by merging life, production and ecology and combining cultivation, conservation, education. In this case, it can manage a sustainable leisure career.

a) Targeting at the development of leisure agriculture, letting people enjoy the beauty of nature

Leisure economy is a new value orientation of the world economy, and leisure agriculture will become the leading industry in the future rural economy. Leisure agriculture emphasizes the integration of "production, life, and ecology", which means the coordinated development of agricultural production, ecology, and the living needs of urban and rural residents.

b) Combining entertainment and education, paying attention to environment protection and ecology education

Flying Cow Ranch promotes outdoor teaching so that visitors can have fun during experience activities and gain knowledge. The agricultural culture and nature experience provided by the ranch not only allows visitors to experience the authenticity and uniqueness of the rural field, but also discovers and recognizes the educational value of the pasture during the recreation experience [24].

c) Being a spiritual habitat and a relaxing place for urban tourists

In developed countries, tourists choose rural vacations to find clean spaces and enjoy a rich traditional culture. It is a higher-level, high-grade tourism behavior, also known as "green vacation" [25]. Therefore, the farm leisure ecotourism is the "wind vane" of future leisure tourism, and people will obtain happiness from the purest environment. 


\subsubsection{Activity Management}

Experience activities and leisure activities are the key points of the Flying Cow Ranch's management. The ranch not only provides accommodation, catering, barbecue and camping activities for tourists with good service facilities, but also finely divides activities, reflecting its excellent performance in standardized management.

1) Itinerary Arrangement

The ranch provides visitors with different itineraries for "one-day trip" and "two-day trip", which helps tourists to effectively plan their own trips and also facilitates the standardized management of the ranch.

\section{2) Children's Activities}

As shown in Table 3, different experience activities for children of different age groups can not only ensure the safety of children's activities, but also help the smooth development of activities.

\section{3) DIY Activities}

DIY activities are self-funded projects, and due to space and time constraints, reservations are required. Flying Cow Ranch publishes the classrooms and time of different DIY activities on the website, so that visitors can make their own arrangements without missing their favorite activities.

To sum up, there are reasonable arrangements for different types of activities, giving visitors a variety of choices, ensuring that each visitor can enjoy the most comfortable activity and the optimal configuration of the ranch's human and nature resources without affecting the normal growth of animals and plants in the pasture.

\subsubsection{Marketing}

The marketing promotion of Flying Cow Ranch is mainly through word-of-mouth promotion and internet marketing.

1) Word-of-Mouth Promotion

Flying Cow Ranch has increased cooperation with schools to enable schoolchildren to know it during the off-campus teaching. When they go home to share their experiences with their parents, the parents will know the ranch, which will attract them to take their children to play when they have time on holidays. And they can also share their experiences with their relatives and

Table 3. Activities for children in different age groups.

\begin{tabular}{ccc}
\hline $\mathbf{3}-\mathbf{7}$ years old & $\mathbf{8}-\mathbf{1 0}$ years old & Over 10 years old \\
\hline Feed ducks & Make cookies & Making a bottle letter \\
Feed little goats & Take care of little cows & Camping \\
Feed rabbits & Paint cows & Be ecological teacher \\
$\begin{array}{c}\text { Ride mini horse or } \\
\text { take carriage }\end{array}$ & Make dairy dessert & Ice cream DIY \\
\hline
\end{tabular}


friends to form a good word-of-mouth effect.

2) Internet Marketing

The network marketing and promotion of Flying Cow Ranch was well-established. It can be seen from the official website that the ranch has clearly and detailedly listed its business philosophy, service, activities arrangement, traffic routes and product description. Besides, people can buy souvenirs and dairy products on the website. The advantages are as follows:

a) These promotion methods save time and effort with high diffusivity.

b) It is convenient for tourists to arrange their own schedules and reduce service pressure of the ranch.

c) Visitors can learn the characteristics of the ranch through the internet, so they can prepare for necessary supplies in advance and have a low-carbon travel.

d) Tourists can get tourism products from the website and purchase them at any place.

\subsection{The ASEB Analysis on Visitors Experience}

This paper uses ASEB grid analysis method to identify the development conditions of the experiential tourism of Flying Cow Ranch from the perspective of tourists experience. The specific analysis is shown in Table 4.

Based on the above analysis, it can be seen that Flying Cow Ranch is very prominent in the advantages and opportunities of experience, as well as activities and environmental resources, which can bring higher profits to the local economic development, and at the same time enable tourists to gain a lot during the tour.

However, we still cannot ignore the disadvantages of "lack of vivid and effective commentary", "narrow audiences", and potential threats in terms of interests and competition.

\section{Comprehensive Review}

\subsection{The Dynamic Mechanism of Flying Cow Ranch}

The dynamic system of leisure agriculture development refers to the dynamic factors that influence the development and change of leisure agriculture. These elements are interdependent and interact to form an organism with certain structure and function [26]. Nancy et al. [27] believe that economic interests are the external motives for developing leisure agriculture while social and cultural values are its intrinsic motives, in addition, owning land resources, economically relying on farm management, and well received by the market are driving factors in stimulating the development of leisure agriculture.

Combined with the development of Flying Cow Ranch, it can be summarized as follows:

1) The original tourism resources (ranch, cow, dairy production) interacted with the market form a relationship between demand and supply, resulting in tourism attractiveness. 
Table 4. The ASEB grid analysis on experiential tourism of flying cow ranch.

\begin{tabular}{|c|c|c|c|c|}
\hline $\begin{array}{l}\text { Evaluation } \\
\text { aspects }\end{array}$ & A(Activities) & S(Settings) & $\mathrm{E}$ (Experiences) & B(Benefits) \\
\hline $\begin{array}{l}\text { S } \\
\text { (Strengths) }\end{array}$ & $\begin{array}{l}\text { SA (Strengths of Activities) } \\
\checkmark \quad \text { Rich experience } \\
\quad \text { programs } \\
\checkmark \quad \text { Unique products } \\
\checkmark \quad \text { Good reputation }\end{array}$ & $\begin{array}{ll}\text { SS } & \text { (Strengths of Settings) } \\
\checkmark & \text { Stay away from downtown } \\
\checkmark & \text { The ranch is well maintained } \\
\checkmark & \text { Educational significant }\end{array}$ & $\begin{array}{ll}\text { SE } & \text { (Strengths of Experiences) } \\
\checkmark & \text { Integration of } \\
& \text { entertainment and } \\
& \text { education } \\
\checkmark & \text { Multiple psychological } \\
& \text { satisfaction }\end{array}$ & $\begin{array}{l}\text { SB (Strengths of Benefits) } \\
\text { For tourists: } \\
\checkmark \quad \text { Increase knowledge } \\
\checkmark \quad \text { Good memories } \\
\checkmark \quad \text { Intimate relationship } \\
\text { For the ranch: } \\
\checkmark \quad \text { Economic benefits }\end{array}$ \\
\hline $\begin{array}{l}\text { W } \\
\text { (Weaknesses) }\end{array}$ & $\begin{array}{l}\text { WA (Weaknesses of } \\
\text { Activities) } \\
\checkmark \quad \text { Large changes in } \\
\quad \text { market demand } \\
\checkmark \quad \text { Activities do not match } \\
\text { the needs of tourists } \\
\checkmark \quad \text { There are overlaps and } \\
\quad \text { restrictions on the time } \\
\text { of activites }\end{array}$ & $\begin{array}{l}\text { WS (Weaknesses of Settings) } \\
\checkmark \quad \text { Limited capacity for pasture } \\
\checkmark \quad \text { More rural space is needed }\end{array}$ & $\begin{array}{l}\text { WE (Weaknesses of } \\
\text { Experiences) } \\
\checkmark \quad \text { Lack of vivid and effective } \\
\text { commentary, the interpreta- } \\
\text { tion effect needs } \\
\text { to be improved } \\
\checkmark \quad \text { Some older visitors think } \\
\text { that some items are only } \\
\text { suitable for children }\end{array}$ & $\begin{array}{l}\text { WB (Weaknesses of } \\
\text { Benefits) } \\
\checkmark \quad \text { The developers gain the } \\
\text { benefit but the interests } \\
\text { of local residents cannot } \\
\text { be guaranteed } \\
\checkmark \quad \text { There are not enough } \\
\text { activities for adults to } \\
\text { benefit every visitor. }\end{array}$ \\
\hline $\begin{array}{l}\text { O } \\
\text { (Opportunities) }\end{array}$ & $\begin{array}{l}\text { OA (Opportunities of } \\
\text { Activities) } \\
\checkmark \quad \text { Solid brand foundation } \\
\checkmark \quad \text { Increasing demand for } \\
\quad \text { travel } \\
\checkmark \quad \text { The popularity of } \\
\quad \text { Taiwan tourism }\end{array}$ & $\begin{array}{ll}\text { OS } & \text { (Opportunities of Settings) } \\
\checkmark & \text { A real and vivid rural } \\
\text { environment } \\
\checkmark \quad \text { Leisure agriculture } \\
\quad \text { receives extensive attention } \\
\checkmark \quad \text { People are eager for the } \\
\quad \begin{array}{l}\text { recreational environment } \\
\text { of village }\end{array}\end{array}$ & $\begin{array}{l}\text { OE (Opportunities of } \\
\text { Experiences) } \\
\checkmark \text { Show more country life } \\
\checkmark \quad \text { Take different experiences } \\
\quad \text { methods } \\
\checkmark \quad \text { Experience different } \\
\quad \text { farming activities }\end{array}$ & $\begin{array}{l}\text { OB (Opportunities of } \\
\text { Benefits) } \\
\checkmark \quad \text { Local residents benefit } \\
\checkmark \quad \text { Visitors also gain }\end{array}$ \\
\hline $\mathrm{T}$ (Threats) & $\begin{array}{l}\text { TA (Threats of Activities) } \\
\checkmark \quad \text { Lack of activity } \\
\text { guidance } \\
\checkmark \quad \text { The advertising range } \\
\text { of the ranch is not } \\
\text { wide enough }\end{array}$ & $\begin{array}{l}\text { TS (Threats of Settings) } \\
\checkmark \quad \text { Whether the infrastructure } \\
\text { and reception facilities can } \\
\text { match the needs of tourists }\end{array}$ & $\begin{array}{l}\text { TE (Threats of Experiences) } \\
\checkmark \quad \text { Traditional farming culture } \\
\text { and old games are weakening } \\
\text { and are easily forgotten } \\
\checkmark \quad \text { Tourists experience } \\
\quad \text { is uncontrollable }\end{array}$ & $\begin{array}{ll}\text { TB } & \text { (Threats of Benefits) } \\
\checkmark & \text { Insufficient allocation } \\
\text { of benefits }\end{array}$ \\
\hline
\end{tabular}

2) Then, due to the benefit loss of operating farms only, the farmland learned from Japan and other places, and began to transform into a leisure farm.

3) The increasing demand for leisure life, recreation, socialization, yearning for the natural environment, accessing to knowledge and other motives further stimulated the development of the Flying Cow Ranch.

4) The local government also attached great importance to the development of leisure agriculture. In the early 1990s, it introduced policies to promote the development of community tourism in agricultural and fishing villages. In 1998, the Association of Leisure Agriculture Development was established to assist agricultural transformation and development of leisure agriculture.

As can be seen in Figure 7, the key factors to develop of Flying Cow Ranch are resources, economic benefits, industry and system basically. It also needs operational guidance such as market guidance, enterprise cooperation and government promotion to play an industrial role. Only with a good foundation 


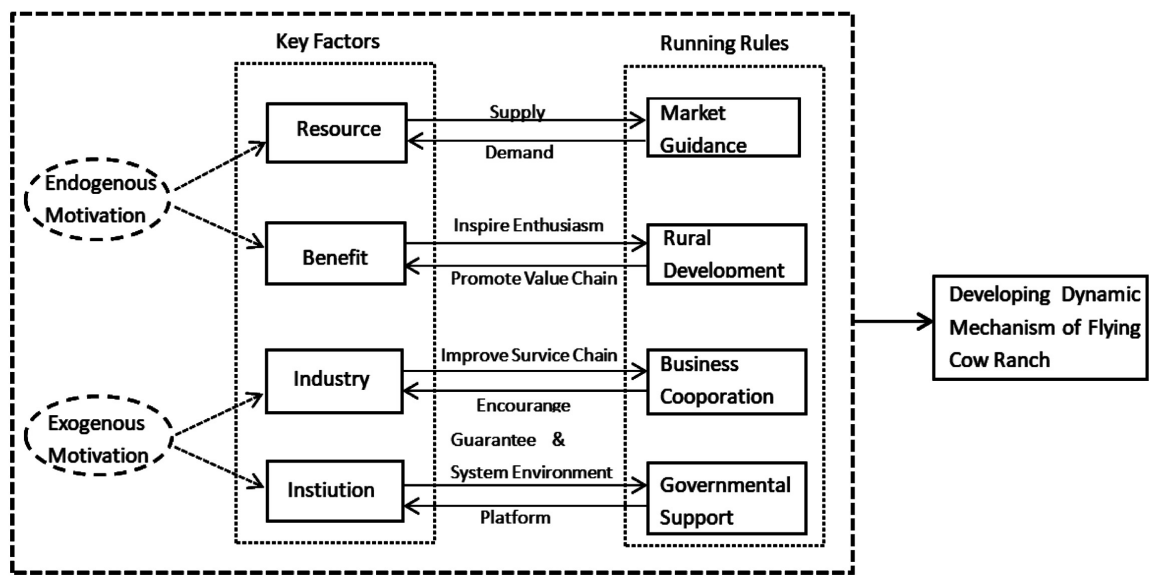

Figure 7. Dynamic mechanism of flying cow ranch.

of key factors that the right rules of operation can make the Flying Cow Ranch form a self-development mechanism providing a continuous source of tendency for its subsequent development.

\subsection{The Operation Mechanism of Flying Cow Ranch}

Combined with the above analysis of the development, management and visitor experience of Flying Cow Ranch, its operating mechanism are as follows:

1) The ranch integrates and optimizes its original basic resources to form distinctive and various tourism resources, and designs experience activities that match the characteristics of the pasture on this basis.

2) Standardized management methods, high-quality resources, and special activities have promoted the benign development of Flying Cow Ranch. Among them, the management method of activities cannot be the same as that of environment resource, because the participation of the person increases flexibility and uncertainty, thus the subdivision management mode is needed.

3) A benignant development of the scenic spot will bring higher economic benefits and achieve the purpose of educating. Economic benefits provide an economic basis for the environmental protection of the pasture. The feedback of education not only makes tourists have a strong perception of environmental protection during the tour, but also this kind of awareness can be extended to their daily life. At the same time, when the educational significance is strong enough, which means the tourists gain a wealth of knowledge, they will be eager to revisit to discover more and update knowledge, so that the economic benefits of the ranch can be strengthened again.

4) Educational significance is the core value of the ranch. It helps visitors to discover nature and enjoy life. Meanwhile, the education-based theory guides the development of various activities which are enriched with education and inspiration. Entertainment experiences without rewards are easy to be forgotten. Therefore, education and experience are mutually inseparable.

The operation mechanism of Flying Cow Ranch is shown in Figure 8. 


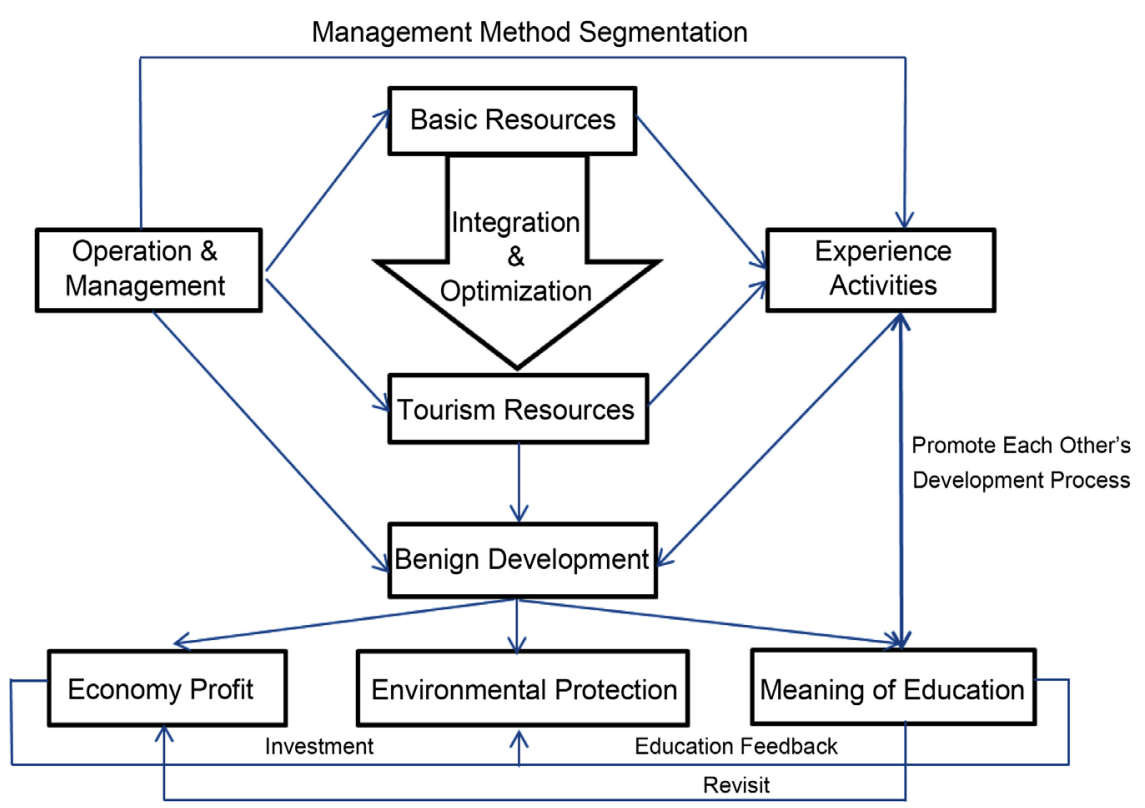

Figure 8. Operation mechanism of flying cow ranch.

\section{Enlightenment and Reference}

\subsection{Resource Innovation}

Flying Cow Ranch refines its agricultural resources into recreation resources, and then transforms the resources through production, life and ecology to bring out creative tourism products with added value, effectively distinguishing itself from homogeneous competitors. This shows that there is no unremarkable landscape, but tourism developers who lack innovation. Each scenic spot can be discovered unique landscape values according to its own characteristics.

\subsection{Leisure Concept}

Flying Cow Ranch has upgraded traditional agricultural resources into leisure resources. We should understand that the core concept of leisure agriculture is "leisure" rather than "hodgepodge", such as "leisure", "sightseeing" and "folk activities". Therefore, during the process of tourism development, a kind of "pureness" and "concentration" should be maintained. Scenic spots should not blindly imitate the landscape construction of other tourist attractions, and profit-seeking is not possible. Only planning under the guidance of core concept can highlight the spots' characteristics and get long-term development.

\subsection{Focus on Experience}

The development of leisure agriculture takes "experience" as its soul. The rich and varied experience projects of the Flying Cow Ranch are significant in attracting visitors. Tourism activity is the result of the interaction between object and subject of tourism, and it is a kind of perception and understanding of people's mind. Therefore, experience projects should be creative, not "plagiar- 
ism", "similarity" or "demagogy". At the same time, it is necessary to deeply explore those experience projects that are compatible with the scenic spots' own resource advantages, therefore, tourists can actively participate and interact, then enhancing the competitiveness of the scenic spots.

\subsection{Tourists Orientation}

The leisure service industry is consumer-oriented, and the tourism development of leisure agriculture is tourist-oriented. Therefore, under the premise of ensuring the protection of ecological environment, "people-oriented" is a guide for tourism development in scenic spots. Meeting the needs of tourists and prioritizing the benefits of tourists is a precondition for a scenic spot's long-term and sustainable development.

\subsection{Standard Management}

The successful operation of Flying Cow Ranch is inseparable from the standardized management system, and the complete set of management regulations help the ranch to operate in an orderly manner. In addition, local policies and laws provide protection for the healthy operation of the pasture. Therefore, a sound and complete legal and regulatory system is a necessary foundation for the development of scenic spots.

\subsection{Digital Marketing}

Effective digital marketing is a necessary means of scenic propaganda. Visitors can learn about the ranch through network and arrange trips in advance. By browsing the real-life photos on the website, visitors are as immersive as they are, and they can have a preliminary perception of the scenic spot. Therefore, the modern management method is worth learning.

\subsection{Double Benefits}

Flying Cow Ranch generates both social benefits and economic benefits. Although the ranch operates for profit, it does not forget to educate the public. Tourists gain knowledge and enjoy meaningful holidays in the process of leisure and enjoyment, which is an important factor to attract tourists to revisit. Therefore, each scenic spot should have its own "mission", providing a place for tourists to relax or convey the idea of educational value for tourists. The scenic spot of "profit-oriented" is bound to be difficult to have long-term development.

In summary, the development of leisure agriculture in mainland China is in a golden period. The development and operation of Flying Cow Ranch can provide a good reference for the construction of leisure agricultural tourism in other areas of China. First of all, we must further promote the "tourism+", "global tourism" and other strategies, relying on unique agricultural tourism resources, promote cooperation between culture, tourism, commerce and other mul- 
ti-sectors, and organize tourism experience activities, so that tourists can experience the pleasure of leisure agricultural tourism. In this case, it will attract tourists from all over the country. At the same time, we should enlarge and strengthen the combination of agriculture and tourism, stimulate the healthy and orderly development of leisure agriculture and rural tourism, and promote the development of leisure agriculture tourism in the direction of high-quality, high-end and differentiation.

\section{Research Limitations and Prospects}

On the one hand, this study only analyzes a case of Flying Cow Ranch. Although this case is typical, it belongs to a kind of leisure pasture, which lacks universality to some extent. In future research, more forms of leisure farms can be analyzed, or multiple forms of farms can be compared and analyzed.

On the other hand, this paper mainly analyzes the successful experience of the operation and management from the perspective of the ranch itself except the ASEB analysis part which explores from tourists perspective. Tourists experience is an important factor in the development of leisure agriculture. Therefore, in the future research, the case study can be analyzed from multiple perspectives, such as tourist experience and tourist satisfaction.

\section{Conflicts of Interest}

The authors declare no conflicts of interest regarding the publication of this paper.

\section{References}

[1] Cheng, C.-C. (1998) Analysis of Leisure Agriculture Marketing Strategy. Agricultural Promotion Aticle Selection, No. 43, 181-182.

[2] Zhang, G.-H. and Bao, W. (2012) Research on Industrialization of Leisure Agriculture in China and Its Model. Inquiry into Economic Issues, No. 10, 30-37.

[3] Fan, Z.-W. (1998) The Main Form of Sightseeing and Leisure Agriculture. World Agriculture, No. 1, 50-51.

[4] Guo, H.-C., Liu, J.-P. and Wang, Y.-C. (2000) The Study on Development of Tourism Agriculture. Economic Geography, 20, 119-124.

[5] Guo, H.-C. (2010) The Significance, Situation and Prospect of Leisure Agriculture in China. Chinese Journal of Agricultural Resources and Regional Planning, 31, 39-42.

[6] Zhang, Z.-G. (2006) The Object, Essence and Characteristics of Leisure Agriculture. Chinese Rural Economy, 22, 73-76.

[7] Liu, Y.-L. (2011) Research on the Core Competitiveness of Leisure Agriculture. Xinxing Publishing Co., Ltd., Zhanghua, 39.

[8] Yuan, D.-M. (2006) Analysis on the Present Situation and Development Countermeasures of Leisure Agriculture in China. Rural Economy, 24, 53-56.

[9] Guo, H.-C. and Ren, G.-Z. (2007) Research on the Current Situation and Countermeasures of Leisure Agriculture Development in China. Journal of Beijing Interna- 
tional Studies University, 13, 66-71.

[10] Tang, B.-L. (2008) Status, Problems and Countermeasures of Leisure Agriculture Industry. Journal of Anhui Agricultural Sciences, 36, 12447-12450.

[11] Wang, Z.-L. and Zhang, G.-C. (2018) Research on the Development Model of Leisure and Sightseeing Ranch Based on the Theory of Experience Economy. Heilongjiang Animal Science and Veterinary Medicine, No. 14, 43-46.

[12] Liu, H.-R., An, Y., Cui, X.-X. (2015) Types of Leisure Agriculture and its Efficiency Evaluation in China. Journal of Northwest A\&F University (Social Science Edition), 15, 83-89.

[13] Hu, B. (2007) The Development History and Current Situation of Taiwan's Leisure Agriculture. Journal of Xi'an University of Posts and Telecommunications, 12, 96-99.

[14] Lin, G.-H. and Zeng, Y.-R. (2007) Discussion on the Development Model and Experience of Taiwan's Leisure Agriculture. Taiwan Agricultural Research, No. 4, 16-21.

[15] Zhang, J. (2011) Revelation from Taiwan Leisure Agriculture Development. Chinese Agricultural Science Bulletin, 27, 288-291.

[16] Li, F. (2008) The Development Model of Taiwan's Leisure Agriculture and Its Enlightenment to the Mainland. Journal of Dongbei University of Finance and Economics, 10, 67-69.

[17] Du, X. and Chen, X. (2013) The Experience and Enlightenment of Taiwan's Leisure Agriculture Development to the Mainland. Research of Agricultural Modernization, 34, 198-201.

[18] Zhou, Q., Zeng, Y. and Yang, X. (2009) A Case Analysis and Enlightenment of Taiwan Leisure Agriculture. Taiwan Agricultural Research, 31, 15-20.

[19] Geng, H. (2011) Experience and Enlightenment of Leisure Agriculture Experience Activities in Taiwan. Journal of Beijing Vocational College of Agriculture, 25, 16-20.

[20] Liu, Y. and Lo, M. (2010) Tourism Attraction Analyses of Flying Cow Ranch. Journal of Rural Tourism Research, 4, 45-61.

[21] Yu, Z. (2013) Research on the Tourism Products of Taiwan Leisure Ranch in the Experience Economy-A Case Study of Weiquan Ranch. Industrial and Science Tribune, 12, 37-38.

[22] Zhou, Q. (2014) Analysis of the Creative Characteristics of Taiwan's Leisure Agriculture. Taiwan Agricultural Research, No. 3, 1-5.

[23] Li, Y. and Niu, Z. (2001) Research on Brand Image Creation in Scenic Spots. Journal of Beijing International Studies University, No. 5, 58-66.

[24] Lin, P.-H. and Lin, H.-S. (2014) Study on Relationships between Knowledge Orientation, Educational Function, Educational Value of Experience Activity in Recreational Farm-A Case of Flying Cow Ranch. Journal of Tourism and Travel Research, 9, 1-17.

[25] Yang, X. (2007) Preliminary Study on Experiencing Rural Tourism Development. Journal of Kunming University, 18, 17-19.

[26] Sheng, X. (2013) Study on the Dynamic Mechanism of Suburban Leisure Agriculture in Coastal Economically Developed Areas. Rural Economy and Science Technology, 24, 113-115. 
[27] Nancy, G., Gehee, M. and Kyungmi, K. (2004) Motivation for Agritourism Entrepreneurship. Journal of Travel Research, 43, 161-170.

https://doi.org/10.1177/0047287504268245 